\title{
Analysis of the Tool Condition Monitoring System Using Fuzzy Logic and Signal Processing
}

\author{
Chidambaram Ramesh Kannan ${ }^{1}$, Palani Padmanabhan ${ }^{2}$ \\ ${ }^{1}$ Department of Mechanical Engineering, Anna University Regional Campus, Madurai, India \\ ${ }^{2} \mathrm{~V} V$ College of Engineering, Tisayanvilai, India \\ Email: *rameshkannan@autmdu.ac.in
}

Received 21 March 2016; accepted 15 April 2016; published 28 July 2016

Copyright (C) 2016 by authors and Scientific Research Publishing Inc.

This work is licensed under the Creative Commons Attribution International License (CC BY). http://creativecommons.org/licenses/by/4.0/

(c) (i) Open Access

\begin{abstract}
In the present investigation, an attempt was made to facilitate tool condition monitoring system on cryogenic treated using fuzzy logic and signal processing. Cryogenic treatment is carried out at $-196^{\circ} \mathrm{C}$ for 48 hours followed on tempering at $200^{\circ} \mathrm{C}$ for 2 hours. The AISI4340 steel is machined with cryogenically treated inserts. Speed, feed and depth of cut are selected as input parameters. The results of the proposed method are encouraged in minimizing tool vibration, flank and crater wear. Good correlation is shown between the neural fuzzy and experimental data. As a result, it is found that cryogenically treated inserts have superior tool wear and vibration resistance, and confirmed by conducting further confirmation tests.
\end{abstract}

\section{Keywords}

Vibration, Cryogenic Temperature, Tool Wear, Fuzzy Logic

\section{Introduction}

Tool wear is one of the major issues in machining and which is substantially influenced by the tool life. A variety of methods namely Physical Vapour Deposition (PVD), Chemical Vapour Deposition (CVD) and thermal spray coatings, are available to increase the tool life by enhancing the surface properties of the tool. Flank and crater wear are the dominant wear mechanism in machining of materials [1]. The tool vibration is the most relative parameter in wear. Deep Cryogenic Treatment (DCT) is an innovative technique to improve wear resistance of tools and an additive process for the conventional heat treatment. Liquid nitrogen is employed in these

\footnotetext{
${ }^{*}$ Corresponding author.
} 
processes at the temperature range $-196^{\circ} \mathrm{C}$. DCT enhances the properties of metals namely strength, toughness, residual stress, crack resistance and more uniform hardness [2].

EN24 steel is high tensile alloy steel renowned for its wear resistance properties and also high strength properties. In general, AISI 4340 is used to make components subject with high stress namely gears, studs, bolts and general engineering applications such as propeller or gear shafts, connecting rods and aircraft landing gear components [3]. In machining processes, the tool wear is resulted by abrasion and adhesion at lower cutting speeds, diffusion, thermal softening and notching at higher cutting speeds. The flank wear formation is a serious problem in machining of materials irrespective of their conditions [4] [5]. In turning process parameters of speed, feed rate and depth of cut are significantly influences the crater wear. The cutting speed increases the depth of crater and decreases the width of the crater wear. The cryogenic treatment improves the wear resistance and hardness by decreasing the retained austenite [6]. Harissingh and Pradeepkumar [7] optimized the turning parameters namely cutting speed, feed rate and depth of cut by machining EN24 steel. It deals with cutting speed and depth of cut are the influencing factors on flank and crater wear. J. Paulo Davim and Luis Figueir [8] evaluated the influence of cutting parameters under flank wear, specific cutting pressure and surface roughness on machinability evaluation in turning of cold work tool steel hardened with ceramic tools using Analysis of Variance (ANOVA). It observed from the higher cutting speed range is the most influencing factors than others. S. Y. Luo et al. [9] studied the wear behavior in the turning of AISI 4340 hardened alloy steels by CBN and ceramic tools. It observed that the factors of cutting speed, cutting forces and temperature had significantly influence the tool wear of CBN and ceramic inserts. Ashok Kumar Sahoo and Bidyadhar Sahoo studied on flank wear, surface roughness, chip morphology and cutting forces in finish hard turning of AISI 4340 steel using uncoated and multilayer TiN and ZrCN coated carbide inserts at higher cutting speed range. It revealed that multi coated inserts were better wear resistance than untreated one.

Numerous studies were carried out to study the effect of cryogenic treatments on the tool materials in machining operations qualitatively. Simranpreetsingh gill et al. [10] observed that shallow cryogenic treatment was notably reduced the flank wear on TiAlN coated inserts. S. thamizhmanii et al. [11] [12] revealed that cryogenic treated inserts formed low flank and crater wear than PVD coated and untreated inserts of milling operations. Ademcicek et al. [13] studied the machinability of cryogenic treated AISIH13 tool steel with ceramic inserts and found that cryogenic treatment decrease the tool wear rate than untreated samples in hard machining process. N.A. Ozbek et al. [14] evaluated the effects of different holding times of deep cryogenic treatment on tool wear in turning of AISI 316 austenitic stainless steel. it found that, the best wear resistance was obtained with cutting inserts cryogenically treated for 24 hours. Hui-Bo He et al. [15] evaluated performance of uncoated and cryogenic treated tools on the CA6104 lathe. It showed that cryogenic treated inserts have better surface finish and less flank wear than untreated inserts. Matteo Strano et al. [16] studied the wear behavior of PVD coated and cryogenically treated tools for Ti-6Al-4V turning and found that cryogenic treatment improves tool life in high rate machining of titanium.

Very few researchers quantitatively studied the effect of cryogenic treatment of difference materials at various machining conditions. Ergun Ekici and Ali Riza Motorcu [17] evaluated the effect of drilling process parameters namely cutting tool, cutting speed and feed rate on the responses of surface roughness and tool life by using Taguchi method. It observed that cryogenic treated drill has positive effect on surface roughness and tool life. Amman Agarwal et al. [18] studied the effect of cutting speed, feed rate, depth of cut, nose radius and cutting environment in CNC turning of AISI P-20 tool steel by using Response Surface Methodology and Taguchi's technique. It revealed that cryogenic environment is the most significant factor in minimizing power consumption followed by cutting speed and depth of cut [19].

The objective of the process investigation is to analysis the effect of process parameter namely speed, feed rate and depth of cut during turning of AISI4340 steel using cryogenically treated cutting tool through fuzzy logic system. In this study, effects of feed rate, depth of cut and cutting speed are given as input parameters to find the tool wear using CNMG120408SMRH13A cutting tools under rough condition. This paper has three sections. The first one deals the experimental details of machining, which includes the preparation of work materials, cryogenic treatment of selected inserts, machine setup and machining of work material. The second section comprises fuzzy interface, statistical analysis and confirmation test.

\section{Experimental Details}

Experimental details of turning, which deals with the preparation of work materials, cryogenic treatment of se- 
lected inserts, machining of work material.

\subsection{Work Material and Cutting Tool}

The AISI4340 steel material of $32 \mathrm{~mm}$ diameter and $150 \mathrm{~mm}$ length has been applied for all the experimental trials. It is procured from sun steels Ltd, Madurai in India. The work piece materials are polished by 400 grit emery paper. The CNMG120408SMRH13A square inserts are chosen for cryogenic treatment. The specifications of insert are as follows, seat size code is 12 . Cutting edge length is $12.8959 \mathrm{~mm}$, insert thickness is 4.7625 $\mathrm{mm}$, cutting edge length is $8.5 \mathrm{~mm}$, nose radius is $0.8 \mathrm{~mm}$. It is purchased from Sanvick India Ltd, Coimbatore.

\subsection{Fast Fourier Transformer}

From Figure 1, a galaxy Midas6 Computer Numerical Control (CNC) universal turning machine was employed to machining the AISI4340 steel specimens for the length of $150 \mathrm{~mm}$ under dry conditions by using cryogenic treated CNMG120408SMRH13A inserts. The specification of machine is maximum diameter of turned shaft is $240 \mathrm{~mm}$, length is $365 \mathrm{~mm}$, the chuck diameter is $169 \mathrm{~mm}$, spindle speed range is 40 to $400 \mathrm{RPM}$ and spindle power is 7.5 KW. The cryogenic treated inserts were mounted on the tool holder. ECLNL-2525M12 tool holder was utilized to mount the inserts. The AISI4340 steel specimens were turned at length of $100 \mathrm{~mm}$ for selected parameters at their levels. The flank and crater wear were selected at the responses which are measured by using the tool maker microscope. The vibration was measured by using dynamometer in model of STSCON 31741. The responses were measured at 50X magnification on the edge of the inserts. The flank and crater wear values are listed in table for different turning conditions. New set of inserts and specimens were used in each experiment and each experiment was repeated at three times for their accuracy.

\subsection{Fuzzy Logic}

Fuzzy logic is one of the most successful of today's technologies for developing sophisticated control systems. It is also popular for its ability to develop rule-based expert systems. Fuzzy controllers and fuzzy reasoning have found particular applications in very complex industrial systems that cannot be modeled precisely even under various assumptions and approximations. Fuzzy model is designed in the Mat lab environment using the fuzzy logic toolbox.

This fuzzy interface system is used to identify the relationship between the responses and experimental design, in order to determine the effectiveness each machining parameters of experimental work. The fuzzy model that has been designed for selecting cutting conditions for the turning operation uses three inputs and two outputs. Speed, feed rate and depth of cut are the input parameters and flank and crater are the output parameters.

The degree of membership that is associated with the categories is shown in Figure 2 and Figure 3. This paper

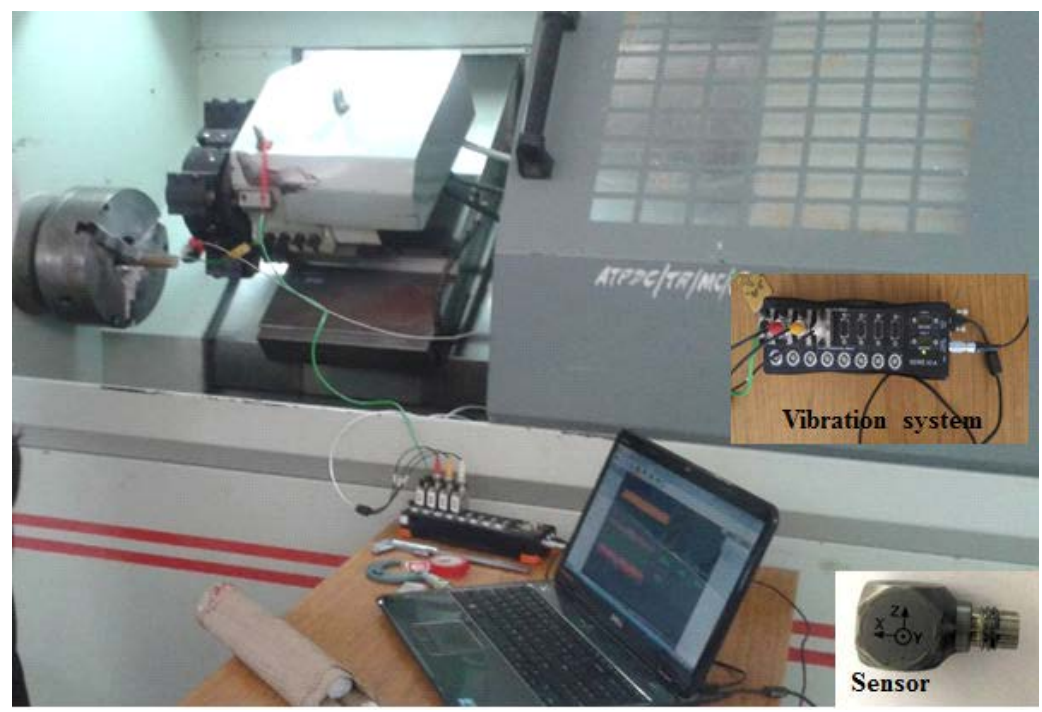

Figure 1. Machining setup with FFT analyzer setup. 

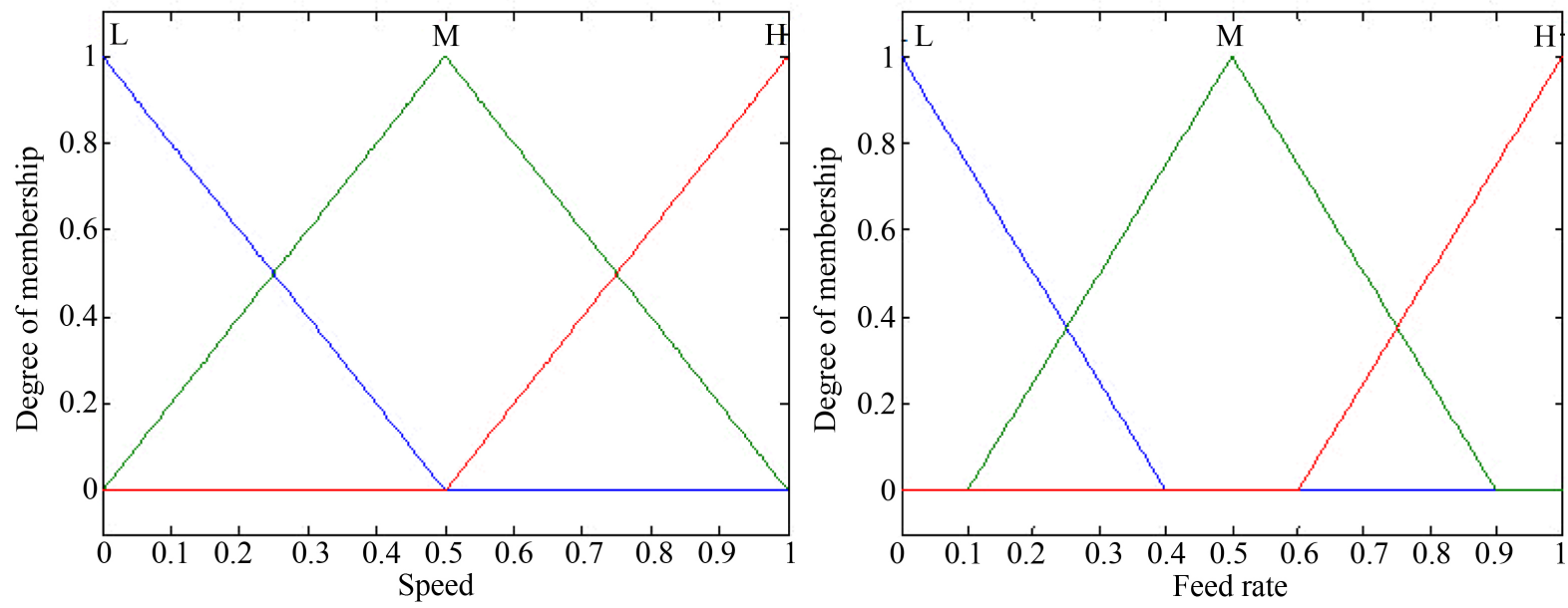

Figure 2. Degree of membership with speed and feed rate.
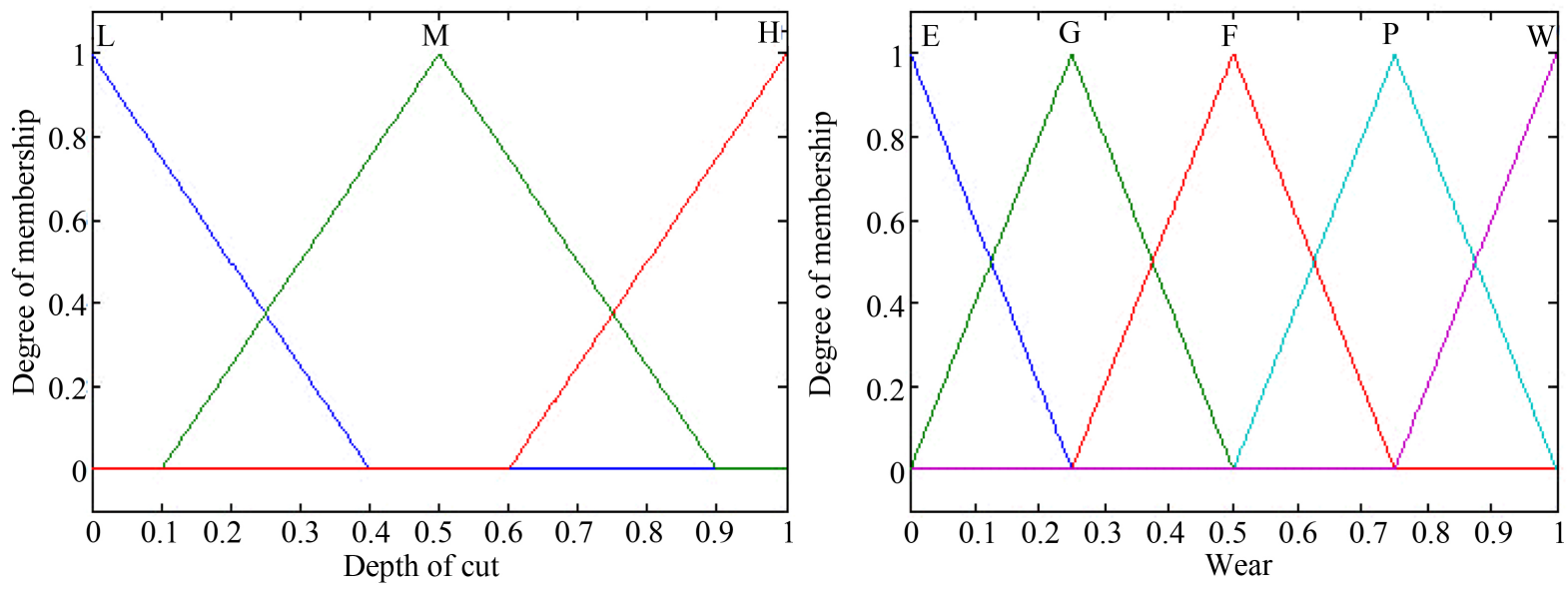

Figure 3. Degree of membership with depth of cut and wear.

compares the fuzzy knowledge base construction methods and the results obtained from the experimental. The paper deals with some specific aspects of fuzzy logic system implementation in cutting tool and wears monitoring.

From Figure 4, the fuzzy inference interface system variation of wear with respect to speed, feed rate and depth of cut. The system frames three inputs and one output of twenty seven rules.

Table 1 represents the input parameters for the fuzzy logic circuit and the wear evaluation of cutting tool inserts. From Figure 5, that there is increase in wear as the increase in speed. As increase in the feed rate causes an increase in the wear. Furthermore, it is well known the larger is the depth of cut greater is the temperature generation, and therefore the tool wear is controlled by the cryogenic treatment. It is proved that the wear deviation is very less for cryogenically treated one. The reduced crater wear happens due to the increased wear resistance of the cryogenically treated insert.

\section{Results and Discussion}

Development of mathematical model based in RSM and the experiments are conducted on tool wear. The responses are consequently expressed in the form of RSM equations as follows.

\subsection{Direct Effect of Flank Wear}

The variation of flank wear with respect to speed is shown in Figure 6. It is observed that the flank wear is increase 
Table 1. Parameters level of fuzzy logic with wear.

\begin{tabular}{|c|c|c|c|c|c|c|c|c|}
\hline \multirow{3}{*}{$\begin{array}{l}\text { Speed } \\
\text { (RPM) }\end{array}$} & \multirow{3}{*}{$\begin{array}{l}\text { FEED } \\
\mathrm{Mm} / \mathrm{rev}\end{array}$} & \multirow{3}{*}{$\begin{array}{l}\text { DOC } \\
\text { () } \mathrm{mm}\end{array}$} & \multicolumn{4}{|c|}{ Wear (RSM) } & \multirow{2}{*}{\multicolumn{2}{|c|}{ Wear (Fuzzy) }} \\
\hline & & & \multicolumn{2}{|c|}{ Flank wear } & \multicolumn{2}{|c|}{ Crater wear } & & \\
\hline & & & $\begin{array}{l}\text { Measured } \\
\text { value } \\
(\mathrm{mm})\end{array}$ & $\begin{array}{l}\text { Predicted } \\
\text { value } \\
(\mathrm{mm})\end{array}$ & $\begin{array}{c}\text { Measured } \\
\text { value } \\
(\mathrm{mm})\end{array}$ & $\begin{array}{l}\text { Predicted value } \\
\text { (mm) }\end{array}$ & Reading & Wear \\
\hline 1250 & 0.1 & 1.5 & 0.5345 & 0.5665 & 0.7811 & 0.6890 & 18.000 & 0.080 \\
\hline 1000 & 0.2 & 1 & 0.3989 & 0.3969 & 0.7022 & 0.7044 & 4.000 & 0.250 \\
\hline 1250 & 0.3 & 1 & 0.4066 & 0.4033 & 0.6655 & 0.6138 & 11.000 & 0.250 \\
\hline 1250 & 0.3 & 0.5 & 0.2767 & 0.2739 & 0.4510 & 0.4841 & 20.000 & 0.250 \\
\hline 1500 & 0.1 & 1.5 & 0.6204 & 0.5875 & 0.5546 & 0.5711 & 2.000 & 0.500 \\
\hline 1250 & 0.1 & 1 & 0.4516 & 0.4242 & 0.5320 & 0.5594 & 3.000 & 0.500 \\
\hline 1000 & 0.2 & 0.5 & 0.2432 & 0.2645 & 0.6523 & 0.5748 & 5.000 & 0.500 \\
\hline 1500 & 0.1 & 1 & 0.4112 & 0.4525 & 0.4981 & 0.4415 & 6.000 & 0.500 \\
\hline 1250 & 0.3 & 1.5 & 0.5812 & 0.5545 & 0.7165 & 0.7434 & 7.000 & 0.500 \\
\hline 1000 & 0.3 & 1 & 0.3932 & 0.3752 & 0.7112 & 0.7316 & 8.000 & 0.500 \\
\hline 1000 & 0.1 & 1.5 & 0.5589 & 0.5465 & 0.7611 & 0.8069 & 9.000 & 0.500 \\
\hline 1500 & 0.2 & 1.5 & 0.5841 & 0.5927 & 0.5454 & 0.5984 & 10.000 & 0.500 \\
\hline 1500 & 0.2 & 1 & 0.4604 & 0.4534 & 0.4957 & 0.4687 & 14.000 & 0.500 \\
\hline 1000 & 0.2 & 1.5 & 0.5423 & 0.5509 & 0.7234 & 0.8341 & 16.000 & 0.500 \\
\hline 1500 & 0.3 & 1 & 0.4102 & 0.4325 & 0.4812 & 0.4959 & 19.000 & 0.500 \\
\hline 1500 & 0.1 & 0.5 & 0.3444 & 0.3393 & 0.3026 & 0.3119 & 1.000 & 0.750 \\
\hline 1250 & 0.2 & 1.5 & 0.5676 & 0.5713 & 0.7244 & 0.7162 & 12.000 & 0.750 \\
\hline 1500 & 0.3 & 0.5 & 0.3004 & 0.3104 & 0.3010 & 0.3663 & 15.000 & 0.750 \\
\hline 1250 & 0.2 & 1 & 0.4286 & 0.4246 & 0.5989 & 0.5866 & 17.000 & 0.750 \\
\hline 1000 & 0.3 & 0.5 & 0.2389 & 0.2384 & 0.6433 & 0.6020 & 13.000 & 0.920 \\
\hline
\end{tabular}

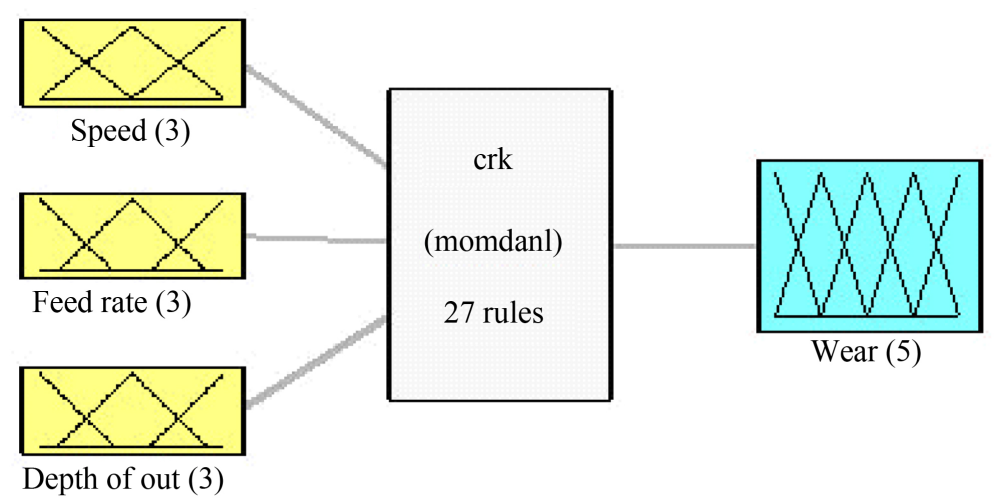

System crk 3 Inputs. 1 outputs. 27 rules

\section{Figure 4. Fuzzy inference system.}

with increasing of speed. The results showed that cutting speed played a significant role in tool wear. Based on the results obtained, it is suggested that cutting speed should remain low when machining AISI4340 in order to achieve maximum cutting performance of the insert tools investigated. 


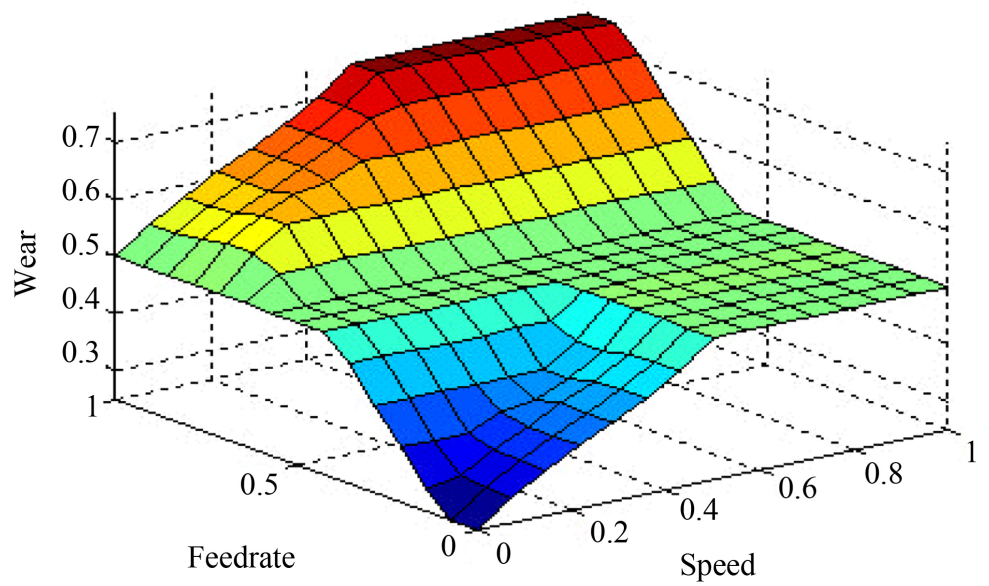

Figure 5. Surface diagram of wear with speed and feed.

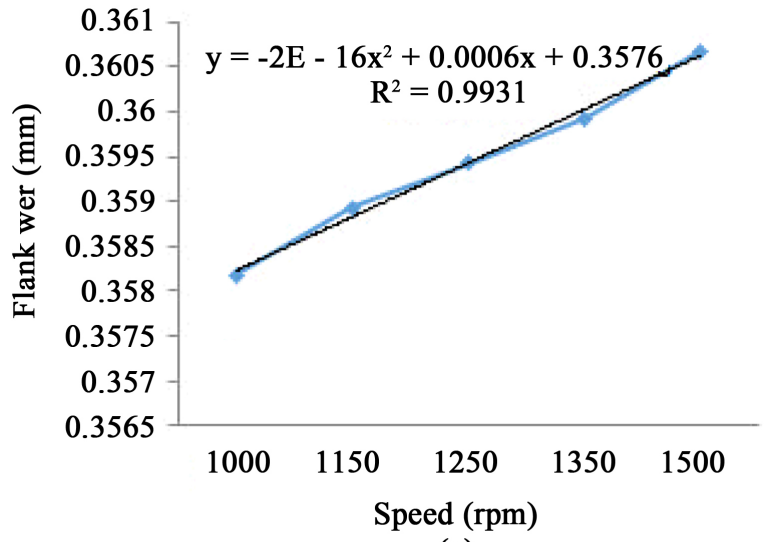

(a)

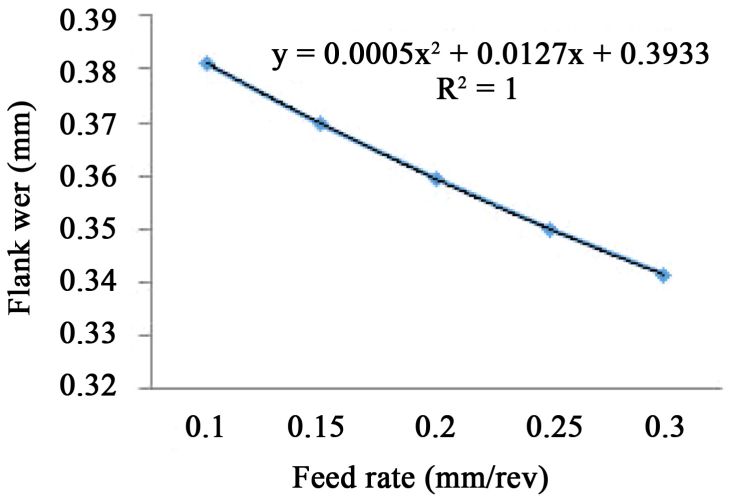

(b)

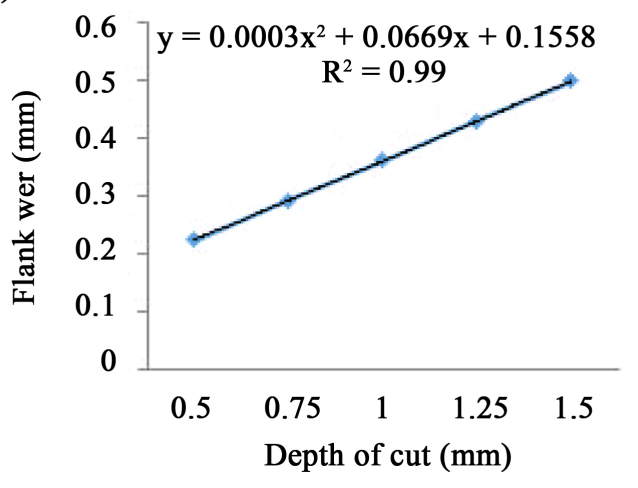

(c)

Figure 6. Variations of flank wear with respect to (a) Speed; (b) Feed rate; (c) Depth of cut.

General structure of proposed model

$$
Y=\beta_{0}+\beta_{1} N-\beta_{2} f+\beta_{3} D+\beta_{11} N^{2}-\beta_{22} f^{2}+\beta_{33} D^{2}+\beta_{12} N f-\beta_{13} N D+\beta_{23} f D
$$

Prediction of wear of proposed model

$$
\begin{aligned}
Y= & 0.4246+0.02824 N-0.01044 f+0.13587 D+0.00052 N^{2}-0.01083 f^{2} \\
& +0.01086 D^{2}+0.00041 N f-0.00735 N D+0.00445 f D
\end{aligned}
$$


While machining the AISI4340 with insert tools, it is observed that the wear growth decreases with increasing feed rate. Evermore, when working at high feed rate, the mechanical and thermal solicitations increase on the cutting edge. As a consequence, friction and high pressures that are exerted on the interface chip-tool and tool-work piece generate wear. As increase in the depth of cut causes an increase in chip tool contact area thereby accelerating the wear. Furthermore, it is well known the larger is the depth of cut greater is the temperature generation, and therefore the tool wear is controlled by the cryogenic treatment.

\subsection{Interaction Effect of Flank Wear}

The effect of an increase in speed followed by the feed rate on the tool wear for tool is presented graphically in Figure 7. It is observed that with increase in cutting speed, there is increase in wear. The results showed that cutting speed played a significant role in tool wear. Based on the results obtained, it is suggested that speed should remain low when machining of AISI4340 in order to achieve maximum cutting performance of the insert tools investigated. It is observed from the Figure that there is increase in wear as the decreasing of feed rate and increase in depth of cut. Furthermore, it is well known the larger is the depth of cut greater is the temperature generation, and therefore grater is the flank wear. The interaction between depth of cut with flank wear, that there is increase in flank wear as the increase in depth of cut.

\subsection{Direct Effect of Crater Wear}

The variation of crater wear with respect to speed is shown in Figure 8. It is observed that the speed is increases when the wear increases for the reason that the cryogenic treatment. It is observed that with increase in cutting speed, there is increase in crater wear. The results showed that cutting speed played a significant role in tool wear. Based on the results obtained, it is suggested that cutting speed should remain low when machining of AISI4340 in

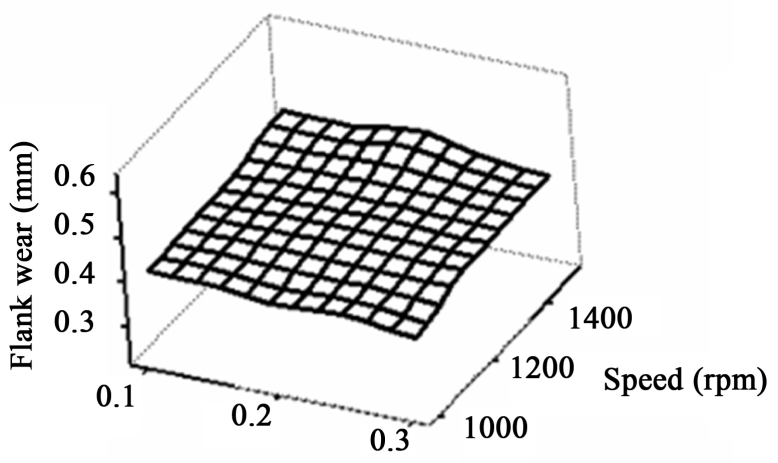

Feed rate $(\mathrm{mm} / \mathrm{rev})$

(a)

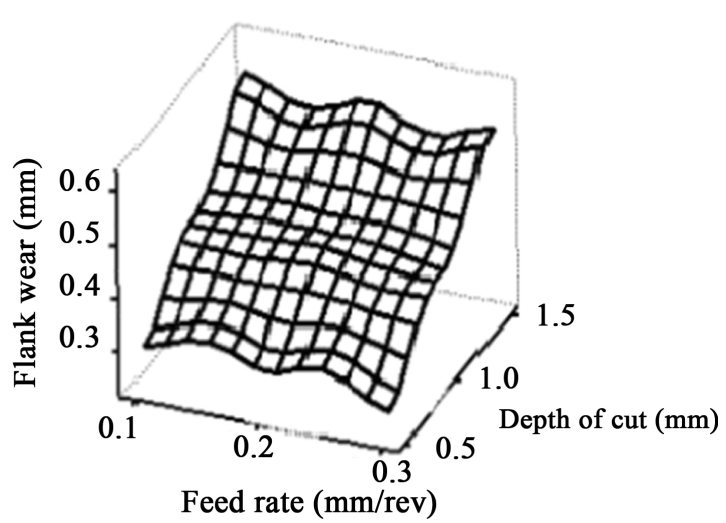

(b)

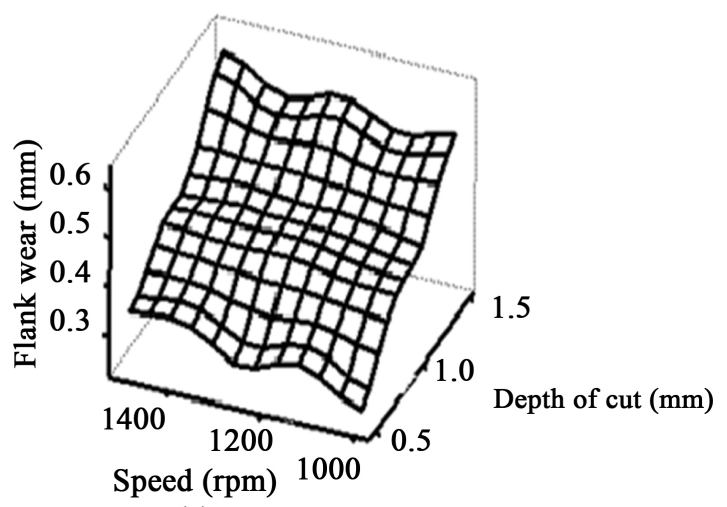

(c)

Figure 7. Interaction between (a) Speed and feed rate; (b) Feed rate and depth of cut; (c) Depth of cut and speed. 


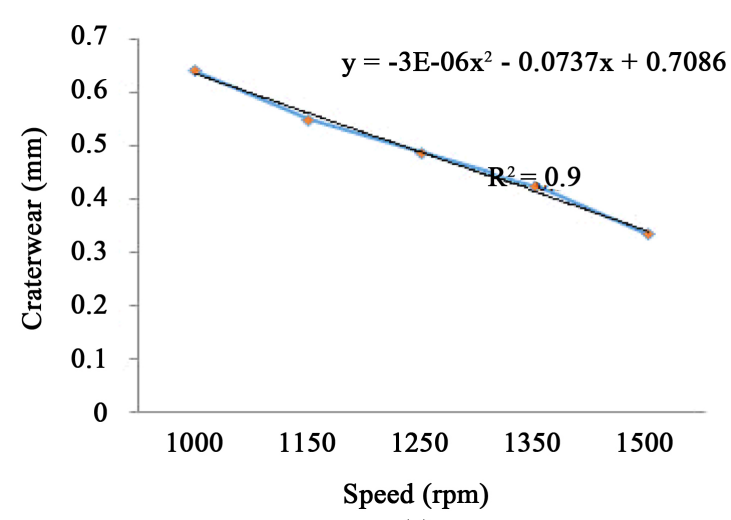

(a)

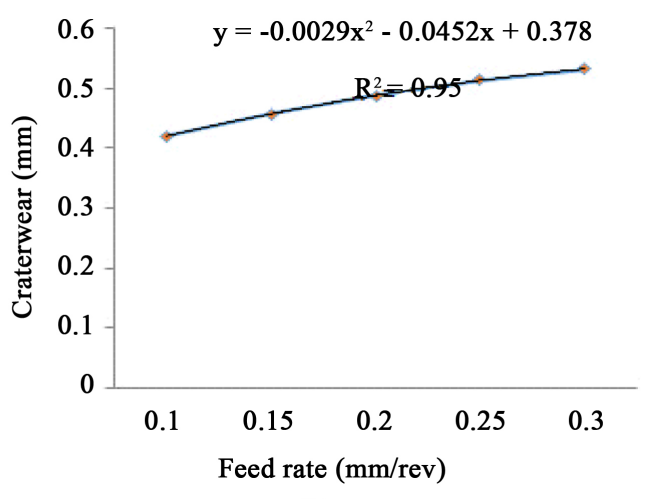

(b)

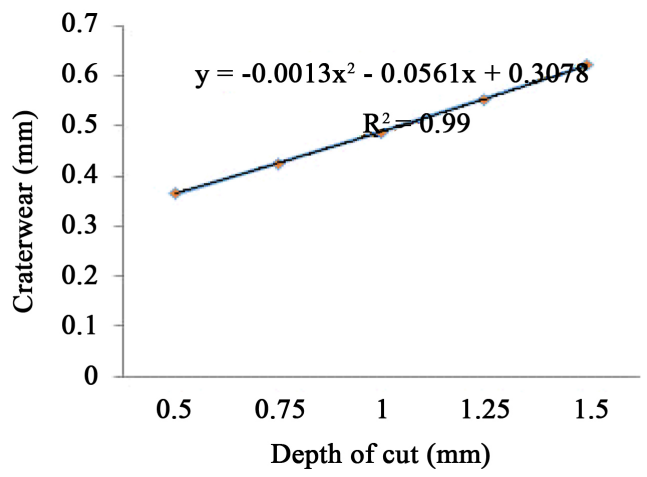

(c)

Figure 8. Variation of crater wear with respect to (a) Speed; (b) Feed rate; (c) Depth of cut.

order to achieve maximum cutting performance of the insert tools investigated.

General structure of proposed model:

$$
Y=\beta_{0}+\beta_{1} N-\beta_{2} f+\beta_{3} D+\beta_{11} N^{2}-\beta_{22} f^{2}+\beta_{33} D^{2}+\beta_{12} N f-\beta_{13} N D+\beta_{23} f D
$$

Prediction of wear of proposed model:

$$
\begin{aligned}
Y= & 0.6027-0.1176 N+0.0271 f+0.1294 D-0.0139 N^{2}+0.0090 f^{2} \\
& -0.0190 D^{2}-0.0134 N f+0.0242 N D+0.0028 f D
\end{aligned}
$$

It is noted that, when the feed rate is constant, the depth of cut is increased. Consequently the crater wear also gradually increased. It shows that the crater wear deviation is very less for cryogenically treated. From the Figure it is understood that, when the depth of cut is increased. Simultaneously, the crater wear also gradually increased. It presents that the crater wear deviation is very less for cryogenically treated insert.

\subsection{Interaction Effect of Crater Wear}

The effect of machining of AISI4340 steel the crater wear is presented graphically in Figure 9. It is observed from the figure, that there is increase in wear as the increasing of feed rate and increase in depth of cut. Furthermore, it is well known the larger is the depth of cut greater is the temperature generation, and therefore bigger is the tool wear.

From the figure, it is understood that, when the depth of cut is increased. Simultaneously, the crater wear also gradually increased. It presents that the crater wear deviation is very less for cryogenically treated insert.

\subsection{Effect of Vibration}

In axial vibration for untreated tool insert, the variation of feed with respect to time and keeping the DOC and speed as constant. The vibration amplitude is low at low speed and it increases slightly at middle speed range and 


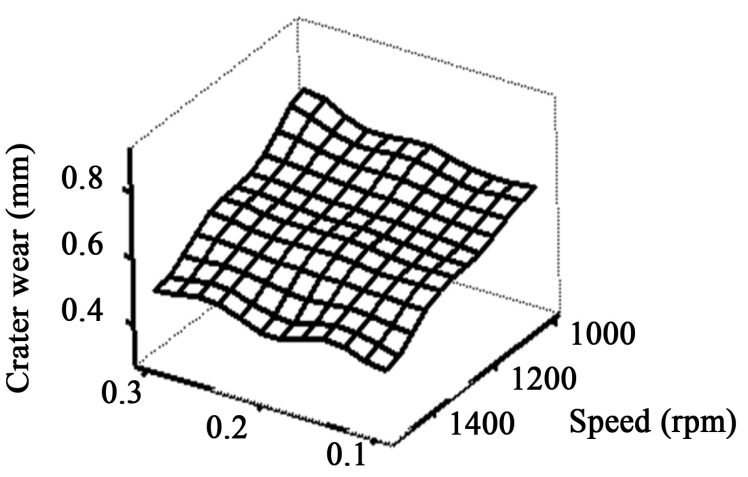

Feed rate (mm/rev)

(a)

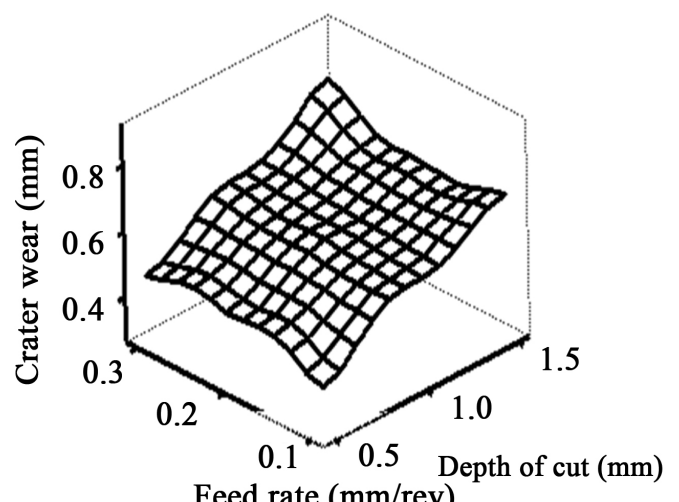

Feed rate $(\mathrm{mm} / \mathrm{rev})$

(b)

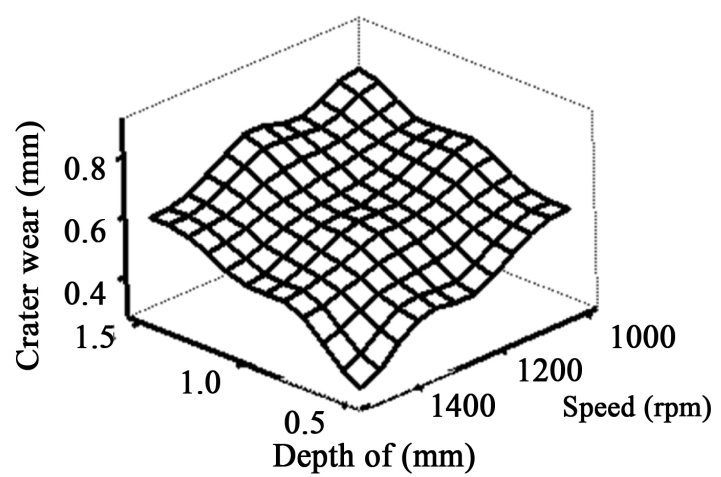

(c)

Figure 9. Interaction between (a) Speed and feed rate; (b) Feed rate and depth of cut; (c) Depth of cut and speed.

again it keep on decrease at high speed. For the treated insert, it is lower than untreated in all feed loads. Speed and feed as constant and varying the DOC. The result shows that the untreated insert has more amplitude of acceleration, as in beginning the vibration is low and it starts increasing at moderate depth of cut and it again starts decreasing at futher depths. The untreated insert the vibration is always high at all depth of cuts. The treated and untreated tool inserts are variation with speed and maintaining constant feed and depth of cut. In axial vibration for untreated insert, the amplitude of vibration is low at low speed and it increases suddenly at middle speed range and again it keep on decrease at high speed. But in case of treated insert, there no sudden variation and it keep on increasing slightly with increasing with speed of feed vibration, tangential vibration and radial vibrations are as shown in Figure 10.

On the other hand, in tangential vibration it follows the same manner as in untreated insert of axial vibration. At the same time the treated insert has a mirror plot of untreated insert. In tangential direction both treated and untreated insert has the same form of vibration and the amplitude of vibration is low in treated insert. Variation of DOC with speed and feed as constant, the amplitude of acceleration were compared for treated and untreated insert in tangential and axial direction.

Analytical method of tool vibration using Fast Fourier Transform are given below.

CASE 1:

In this case 1 , speed is taken as output and feed is taken as input with constant depth of cut 0.3 .

Output: $S=\{500,750,1000,1250,1500\}$

Input: $I=\{0.1,0.2,0.3,0.4,0.5\}$

$D=\{0.3\} \quad S(F)=\sum_{I=0.1}^{0.5} S(t) \mathrm{e}^{(-j 2 \pi(0.3) / N)}$

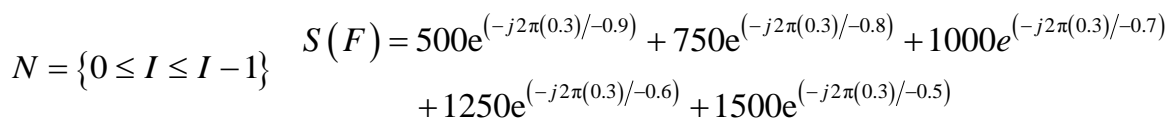



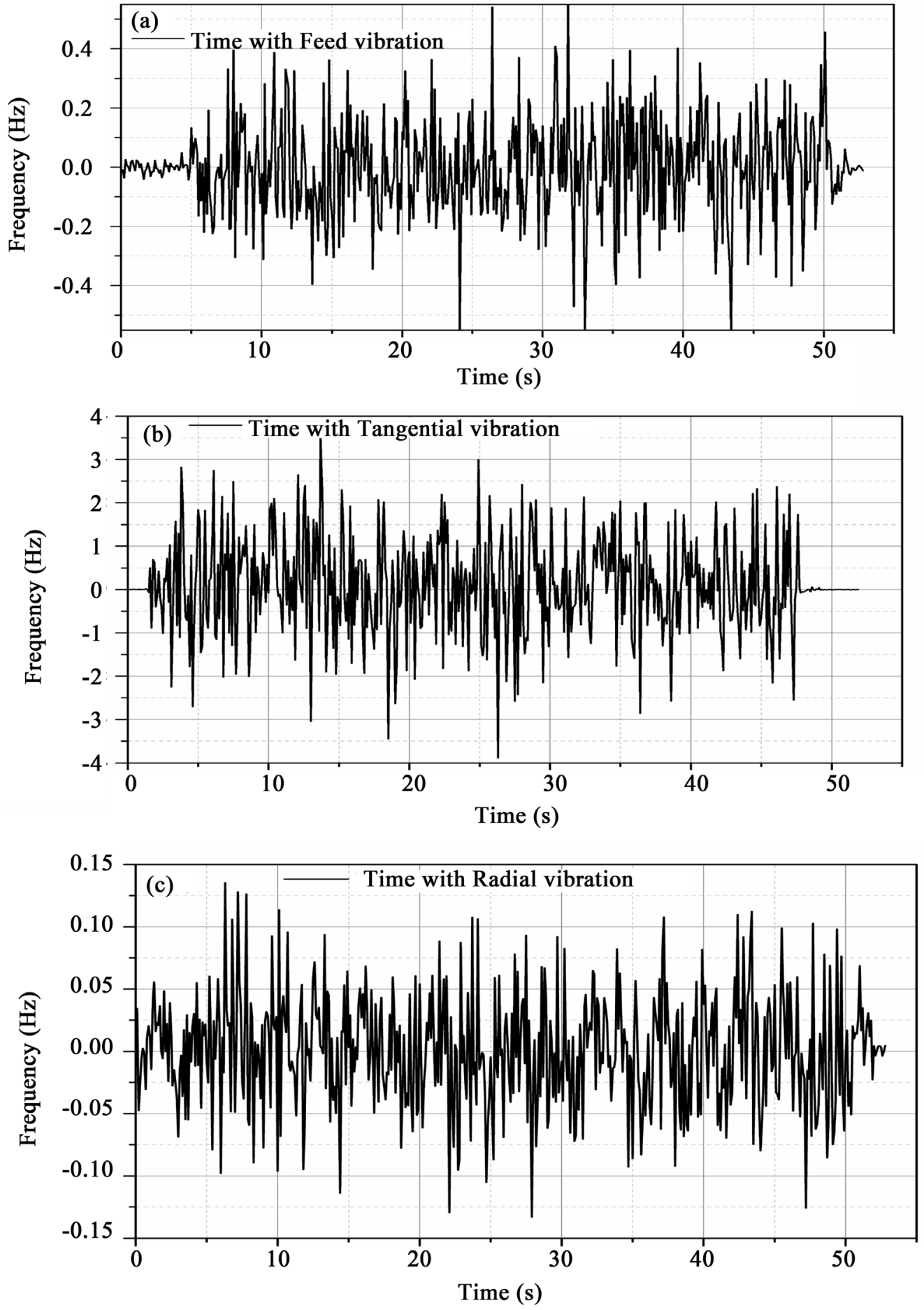

Figure 10. Acceleration with time and frequency diagram.

$$
\begin{gathered}
S(F)=500 \mathrm{e}^{j \frac{2 \pi}{3}}+750 \mathrm{e}^{\frac{3 \pi}{4}}+1000 \mathrm{e}^{j 0.857 \pi}+1250 \mathrm{e}^{j \pi}+1500 \mathrm{e}^{j .2 \pi} \\
S(F)=500[-0.5+j 0.8660]+750[-0.7071+j 0.7071] \\
+1000[-0.9007+j 0.4342]+1250[-1]+1500[-0.809-j 0.5877]
\end{gathered}
$$




$$
S(F)=-4144.52+j 515.975
$$

CASE 2:

In this case 2, feed is taken as output and speed is taken as input with constant depth of cut 0.3.

Input: $S=\{500,750,1000,1250,1500\}$

Output: $I=\{0.1,0.2,0.3,0.4,0.5\}$

$D=\{0.3\}$

$$
\begin{gathered}
I(F)=\sum_{I=500}^{1500} I(t) \mathrm{e}^{(-j 2 \pi(0.3) / N)} \\
N=\{0 \leq S \leq S-1\} \\
I(F)=0.1 \mathrm{e}^{\left(-j 0.6 \pi \frac{2 \pi}{-499}\right)}+0.2 \mathrm{e}^{\left(-j \frac{0.6}{2 \pi}-749\right)}+0.3 \mathrm{e}^{\left(-j \frac{0.6 \pi}{0.3}-999\right)}+0.4 \mathrm{e}^{(-j 0.6 \pi /-1249)}+0.5 \mathrm{e}^{(-j 0.6 \pi /-1499)} \\
I(F)=0.1[0.9999+j 0.0037]+0.2[0.9999+j 0.00251]+0.3[0.9999+j 0.0018] \\
+0.4[0.9999+j 0.0015]+0.5[0.9999-j 0.00125] \\
I(F)=1.49985+j 0.00263
\end{gathered}
$$

The dynamic motion between the tool and the work piece is a complicated positive and negative positions from

Figure 11, obtain the positive and the negative frequency are visible using FFT analyser. The tangential, feed
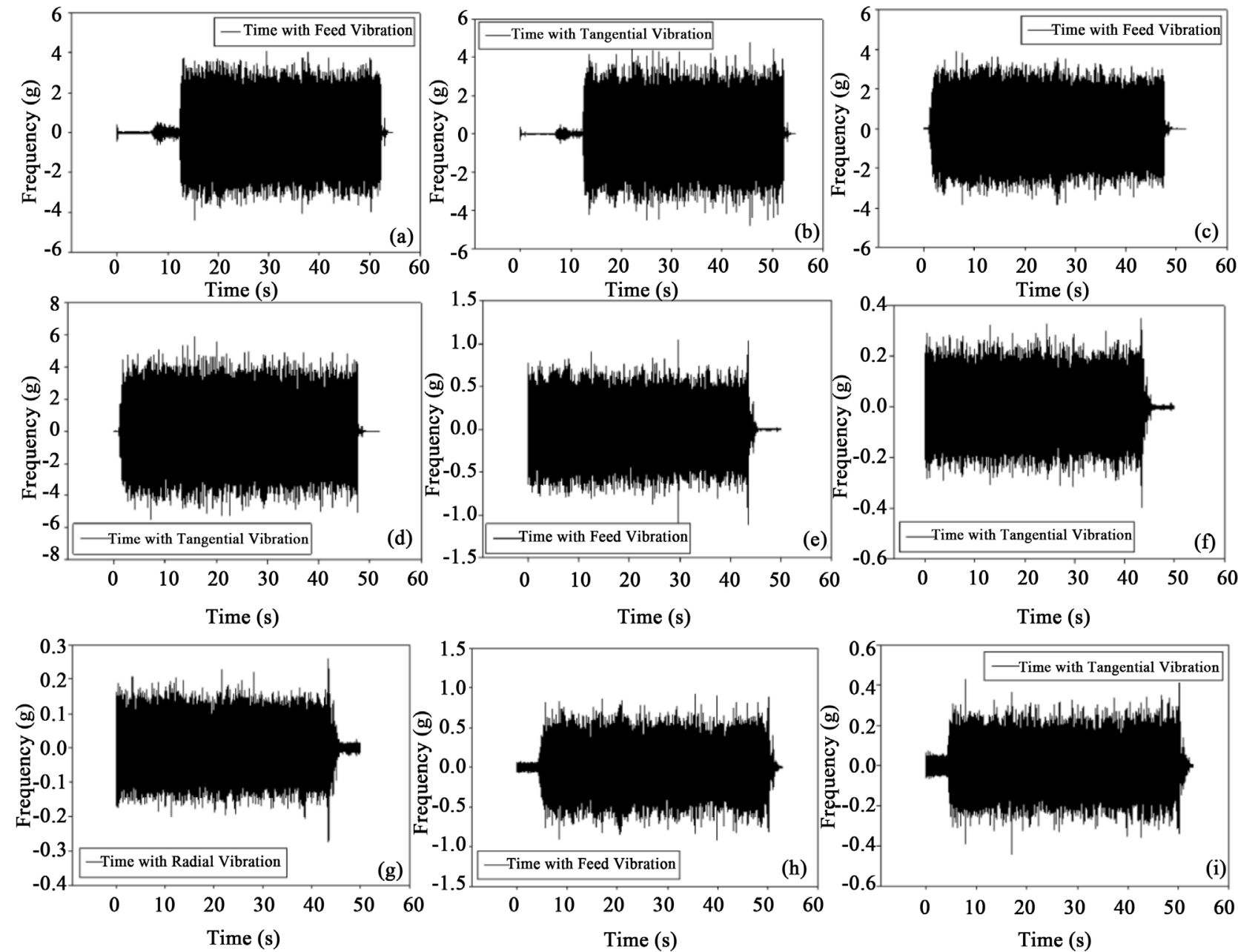

Figure 11. Frequency domain of time with vibration. 

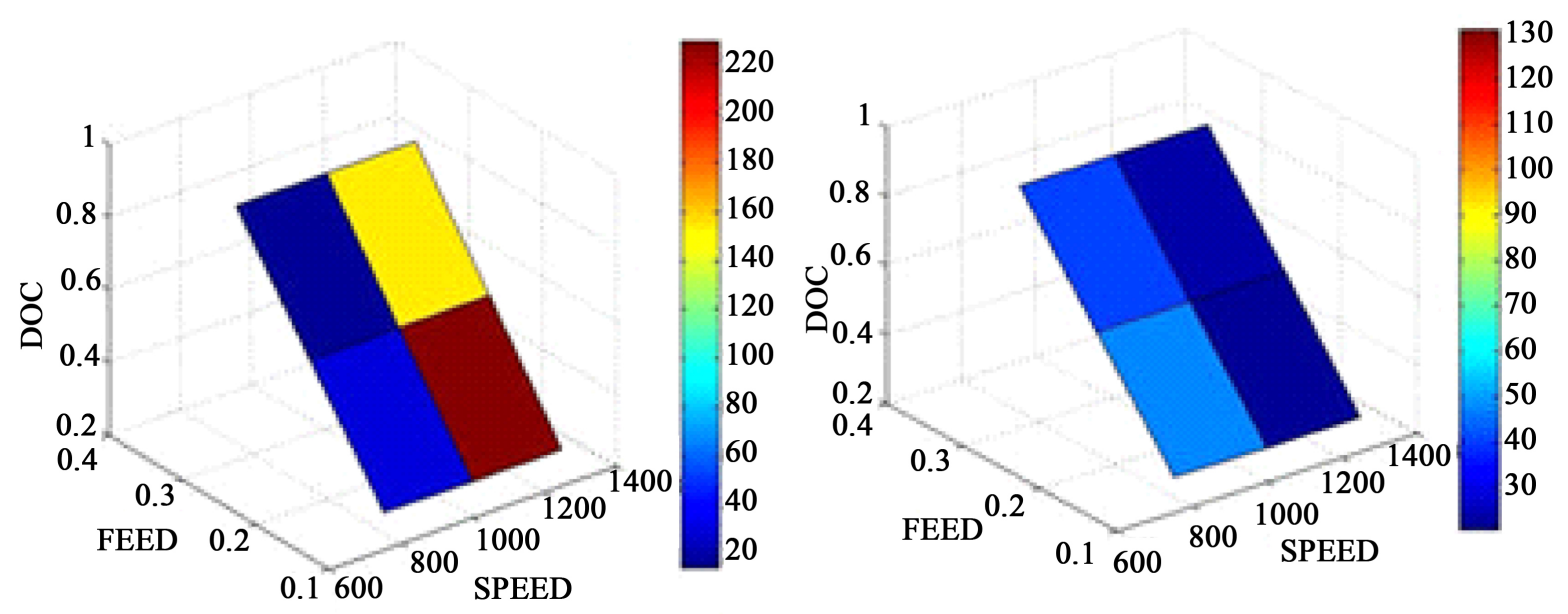

Figure 12. Stability limits with speed, feed and depth of cut.

and radial vibrations are increasing with increase of speed with respect to time. It is directly depended the selected input parameters.

\subsection{Stability Lobe Diagram}

The stability lobe diagram describes the tool vibration under different machining parameters. By constructing the stability lobe diagram the untreated inserts has high amplitude of vibration as a magnitude of $220 \mathrm{~m} / \mathrm{s}^{2}$ and for the cryogenically treated insert which has more stability grains survives under the same machining parameter of untreated insert and produces less amplitude of vibration as $130 \mathrm{~m} / \mathrm{s}^{2}$ during machining in Figure 12.

\section{Conclusion}

The cryogenic treatment improves the hardness by formation of $\eta$-carbides of the insert. The selected parameters influence the tool wear and vibration significantly. Depth of cut is the most influencing factor followed by cutting speed and feed rate for tool wear and tangential vibration. The feed vibration decreased with increasing the speed and increased with increasing of depth of cut. The adequacy of the model has been tested by fuzzy logic system. Neural fuzzy, based on experiments is a very efficient way of calculating flank and crater wear can be followed during the industrial machining process with the same tooling and setup. The fast Fourier Transform analyzer has been tested by FFT accelerator system. The comparison between prediction and experimental details shows that the proposed model agrees with in wear observation on speed is $1000 \mathrm{rpm}$, feed rate is $0.1 \mathrm{~mm} / \mathrm{rev}$, and the depth of cut is $0.5 \mathrm{~mm}$ with respect the wear $5.45 \mathrm{~mm}$ is the optimum value. The vibration increased with increasing the selected parameters. It is suggested that the vibration is controlled the tool wear and tool life of the cutting tool insert.

\section{References}

[1] Liu, K., Li, X., Rahman, M. and Liu, X. (2003) CBN Tool Wear in Ductile Cutting of Tungsten Carbide. Wear, 255, 1344-1351. http://dx.doi.org/10.1016/S0043-1648(03)00061-9

[2] Dossett, J. and Totten, G. (2013) Cold and Cryogenic Treatment of Steel. ASM Hand Book, Steel Heat Treating Fundamentals and Process, Vol. 4, 382-386

[3] Bhateja, A., Bhardwaj, J., Singh, M. and Pal, S.K. (2013) Optimization of Different Performance Parameters i.e. Surface Roughness, Tool Wear Rate \& Material Removal Rate with the Selection of Various Process Parameters Such as Speed Rate, Feed Rate, Specimen Wear, Depth of Cut in CNC Turning of EN24 Alloy Steel—An Empirical Approach. The International Journal of Engineering and Science, 2, 103-113.

[4] Jeon, J. and Kim, S. (1988) Optical Flank Wear Monitoring of Cutting Tools by Image Processing. Wear, 127, 207217. http://dx.doi.org/10.1016/0043-1648(88)90131-7

[5] Chou, Y.K. and Evans, C.J. (1997) Tool Wear Mechanism in Continuous Cutting of Hardened Tool Steels. Wear, 212, 59-65. http://dx.doi.org/10.1016/S0043-1648(97)00139-7

[6] Panigrahi, S.K. and Jayaganthan, R. (2011) Effect of Annealing on Thermal Stability, Precipitate Evolution, and Me- 
chanical Properties of Cryorolled Al 7075 Alloy. Metallurgical and Materials Transactions A, 42, 3208-3217. http://dx.doi.org/10.1007/s11661-011-0723-y

[7] Singh, H. and Kumar, P. (2004) Tool Wear Optimization in Turning Operation by Taguchi Method. Indian Journal of Engineering and Materials Sciences, 11, 19-24.

[8] Davim, J.P. and Figueira, L. (2007) Machinability Evaluation in Hard Turning of Cold Work Tool Steel (D2) with Ceramic Tools Using Statistical Techniques. Materials \& Design, 28, 1186-1191. http://dx.doi.org/10.1016/j.matdes.2006.01.011

[9] Luo, S., Liao, Y. and Tsai, Y. (1999) Wear Characteristics in Turning High Hardness Alloy Steel by Ceramic and CBN Tools. Journal of Materials Processing Technology, 88, 114-121. http://dx.doi.org/10.1016/S0924-0136(98)00376-8

[10] Gill, S.S., Singh, R., Singh, H. and Singh, J. (2009) Wear Behaviour of Cryogenically Treated Tungsten Carbide Inserts under Dry and Wet Turning Conditions. International Journal of Machine Tools and Manufacture, 49, $256-260$. http://dx.doi.org/10.1016/j.ijmachtools.2008.11.001

[11] Thamizhmanii, S. and Hasan, S. (2006) Analyses of Roughness, Forces and Wear in Turning Gray Cast Iron. Journal of Achievements in Materials and Manufacturing Engineering, 17, 401-404.

[12] Thamizhmanii, S., Nagib, M. and Sulaiman, H. (2011) Performance of Deep Cryogenically Treated and Non-Treated PVD Inserts in Milling. Journal of Achievements in Materials and Manufacturing Engineering, 49, 460-466.

[13] Çiçek, A., Kara, F., Kivak, T. and Ekici, E. (2013) Evaluation of Machinability of Hardened and Cryo-Treated AISI H13 Hot Work Tool Steel with Ceramic Inserts. International Journal of Refractory Metals and Hard Materials, 41, 461-469. http://dx.doi.org/10.1016/j.ijrmhm.2013.06.004

[14] Özbek, N.A., Çiçek, A., Gülesin, M. and Özbek, O. (2014) Investigation of the Effects of Cryogenic Treatment Applied at Different Holding Times to Cemented Carbide Inserts on Tool Wear. International Journal of Machine Tools and Manufacture, 86, 34-43. http://dx.doi.org/10.1016/j.ijmachtools.2014.06.007

[15] He, H.-B., Han, W.-Q., Li, H.-Y., Li, D.-Y., Yang, J., Gu, T., et al. (2014) Effect of Deep Cryogenic Treatment on Machinability and Wear Mechanism of TiAlN Coated Tools during Dry Turning. International Journal of Precision Engineering and Manufacturing, 15, 655-660. http://dx.doi.org/10.1007/s12541-014-0384-z

[16] Strano, M., Albertelli, P., Chiappini, E. and Tirelli, S. (2015) Wear Behaviour of PVD Coated and Cryogenically Treated Tools for Ti-6Al-4V Turning. International Journal of Material Forming, 8, 1-11. http://dx.doi.org/10.1007/s12289-014-1215-6

[17] Ekici, E. and Motorcu, A.R. (2014) Evaluation of Drilling Al/SiC Composites with Cryogenically Treated HSS Drills. The International Journal of Advanced Manufacturing Technology, 74, 1495-1505. http://dx.doi.org/10.1007/s00170-014-6085-z

[18] Aggarwal, A., Singh, H., Kumar, P. and Singh, M. (2008) Optimizing Power Consumption for CNC Turned Parts Using Response Surface Methodology and Taguchi's Techniquea Comparative Analysis. Journal of Materials Processing Technology, 200, 373-384. http://dx.doi.org/10.1016/j.jmatprotec.2007.09.041

[19] Sharma, P., Verma, A., Sidhu, R. and Pandey, O. (2005) Process Parameter Selection for Strontium Ferrite Sintered Magnets Using Taguchi L9 Orthogonal Design. Journal of Materials Processing Technology, 168, 147-151. http://dx.doi.org/10.1016/j.jmatprotec.2004.12.003

\section{Submit or recommend next manuscript to SCIRP and we will provide best service for you:}

Accepting pre-submission inquiries through Email, Facebook, LinkedIn, Twitter, etc. A wide selection of journals (inclusive of 9 subjects, more than 200 journals)

Providing 24-hour high-quality service

User-friendly online submission system

Fair and swift peer-review system

Efficient typesetting and proofreading procedure

Display of the result of downloads and visits, as well as the number of cited articles

Maximum dissemination of your research work

Submit your manuscript at: http://papersubmission.scirp.org/ 